\title{
O manifesto "Arquitetura sacra futurista (predomínio do vidro e do alumínio)" de Fillia
}

Vanessa Beatriz Bortulucce*

O presente texto apresenta, pela primeira vez em língua portuguesa, a tradução do manifesto Arquitetura sacra futurista (predomínio do vidro e do alumínio) escrito em 1932 pelo artista e teórico italiano Luigi Colombo (1904-1936), usualmente conhecido nos círculos artísticos como Fillia. O artista fez parte da segunda geração de poetas, artistas e teóricos futuristas que conduziram o movimento para além da Primeira Guerra Mundial. Ele foi autor de poesias, contos e peças teatrais, pintor autodidata, jornalista, ativista político e editor que dedicou sua vida para a sua pesquisa artística e o avanço da poética futurista. Publicou obras sobre arquitetura moderna, culinária e design, colaborando intensamente com Marinetti e outros importantes intelectuais de seu tempo. Fillia foi um personagem único entre os Futuristas, devido às suas qualidades pessoais e espirituais que permearam a sua visão de mundo e as suas obras. Profundamente influenciado pelos impulsos destrutivos e reconstrutivos do Futurismo, impôs sua filosofia pessoal no movimento, tornando-se uma figura fortemente influenciadora na poética do grupo nos anos 20 e no início da década seguinte.

Luigi Colombo nasceu em Rovello, em 1904, e morreu em Turim, em 1936. Poeta e pintor, cresceu nesta última cidade, onde continuou a trabalhar, com exceção de poucas visitas a Paris. Em 1923, com Tullio Alpinolo Bracci e Ugo Pozzi, fundou o Movimento Futurista Turinês e o Sindicato dos Artistas Futuristas, que abraçaram a perspectiva revolucionária do proletariado da classe trabalhadora urbana. Durante os anos vinte e trinta, estes dois grupos formaram o coração de um dos mais importantes grupos futuristas na Itália, e Fillia permaneceu líder absoluto.

A partir de 1922, além de pinturas apresentadas nas exibições futuristas, ele atuou no design de interiores (Ambiente Novatore, Turim, 1927), mobiliário e objetos de decoração, incluindo cerâmica (com Tullio d'Albisola). Escreveu manifestos futuristas e ensaios sobre arte e arquitetura que usualmente apareciam em revistas que eram editadas e publicadas por ele ( $L a$ Città Futurista, Vetrina Futurista, La Città Nuova, Stile Futurista) e em monografias ou

\footnotetext{
* Doutora em História pela UNICAMP, professora do UNIFAI e da USJT.
} 
antologias: La Nuova Architettura (1931), Il Futurismo (1932), Gli Ambienti della nuova architettura (1935). Também escreveu poesia na estética das palavras em liberdade, como os quarenta poemas publicados no volume organizado por Marinetti Inuovi poeti futuristi, novelas, peças como La morte della donna, Lussuria radio elettrica, Sensualità - Teatro d'eccezione (1925), L'uomo senza sesso (1927), todas baseadas no mito poético das máquinas e expressando uma sensualidade "maquinista".

O conjunto da obra de Fillia exerceu enorme influência no Futurismo dos anos 20, o que conduziu às imagens religiosas da chamada "arte sacra futurista", em um movimento que até então estava fortemente caracterizado como materialista e anti-religioso, culminando no "Manifesto da Arte Sacra Futurista" (1931), apresentado neste livro. Tais manifestos se explicam pelo fato de que, ao longo de sua carreira, Fillia colocou uma significativa ênfase no aumento do caráter espiritual do futurismo na tentativa de concluir o processo de elevar sua ideologia a uma religião adequada para as pessoas que viviam na "era da máquina." Uma de suas contribuições mais importantes foi a tentativa de recuperar e redefinir o "homem futurista", ressaltando a importância da identidade pessoal e experiência espiritual através de novas formas de representação visual-verbal.

Nos estágios iniciais de sua carreira, Fillia lutou para trabalhar com a noção de uma identidade futurista coletiva, pesquisando por maneiras de defini-la politicamente e esteticamente. Determinado a usar a arte e literatura para propósitos políticos e sociais, em 1922 Fillia foi coautor de um volume de poemas em verso livre junto com dois outros poetas, Galeazzi e Pasquali (dos quais sabemos muito pouco), $1+1+1=1$. Dinamite. Poesie Proletarie. Rosso+Nero $(1+1+1=1$. Dinamite. Poesias Proletárias. Vermelho + Preto, inédito em língua portuguesa), com o intuito de criar uma visão futurista coletiva inspirada pelas ideias de esquerda que circulavam em Turim. No entanto, logo após a publicação de Dinamite, Fillia se afastou das experiências com a identidade coletiva, mudando para uma abordagem mais pessoal, individualizada, ao mesmo tempo em que se direcionava para a direita política, mais afinada com Marinetti e com o movimento futurista como um todo. Neste tempo, passou a defender, cada vez mais fortemente, uma postura espiritualizada para o movimento, que não estivesse apenas voltada para fins meramente políticos ou estéticos.

Sua participação como escritor de manifestos dentro do movimento foi marcante. Em 1925, Fillia e Tullio Alpinolo Bracci publicaram dois manifestos sobre a arte futurista. "Alfabeto spirituale" ("Alfabeto espiritual), foi publicado no catálogo de uma exposição realizada no Palazzo Madama, em Turim, e "La pittura spirituale" (“A pintura espiritual”) foi 
publicado em março na L'Impero, um jornal futurista de orientação fascista, situado em Roma. Um terceiro manifesto, desta vez escrito somente por Fillia, "L'idolo meccanico" ("Ídolo Mecânico") - também título de uma de suas telas, realizada em 1925 - também apareceu nas páginas de L'Impero.

Sua evolução pictórica como pintor possui três períodos diferentes: o primeiro, por volta de meados dos anos vinte, é o seu período "mecânico" abstrato, em que cores brilhantes e sem matizes sugerem analogias psicológicas; no final dos anos vinte ele desenvolveu um agudo plasticismo "mecânico", e, finalmente, no início dos anos trinta, as influências de Prampolini foram projetadas em uma dimensão fantástica e cósmica. Para Fillia, a arte não se trata somente de um ato estético: ela está intrinsecamente ligada à ideologia social e política, bem como à espiritualidade. A nova realidade, fruto da sociedade tecnológica, necessita de novas formas de interpretação e compreensão da existência. Trata-se, aqui, de uma nova postura poética do futurismo, que, em seus primeiros anos, não se ocupava em refletir as questões ligadas à espirtualidade do homem. Em Fillia, testemunhamos a enorme importância dada para a natureza espiritual das relações entre arte e vida, derivadas, em parte, pela nova configuração da Europa após o final da Primeira Guerra, e o zeitgeist do chamado "retorno à ordem". Tal ênfase nos aspectos psicológicos e espirituais marca um novo direcionamento na poética futurista; a arte pode, agora, servir também como uma experiência transcendente.

Contudo, a teoria da espiritualidade de Fillia é marcadamente voltada para o indivíduo, e não para um grupo, o que o distancia de explicações que atribuem esta sua visão exclusivamente às tendências religiosas do regime fascista, uma vez que estas estavam fortemente voltadas para o coletivo. Os estudos de Fillia, neste sentido, também estão afinados com as tendências intelectuais internacionais e os estudos sobre espiritualidade que se aplicavam nas artes plásticas, notadamente no campo da pintura abstrata; aqui, Kandinsky é o exemplo paradigmático. As teorias da cor espirituais de Fillia possuem relação com a teosofia, com os escritos de Jacques Maritain (1882-1973), filósofo francês neotomista, dentre outras tendências em voga no ambiente europeu.

Além dos textos que abordam a arte e suas relações com a espiritualidade e o sagrado, Fillia produziu vários textos sobre arquitetura, alguns deles apresentados neste livro. A arquitetura é um dos campos que mais escritos recebeu dos futuristas. Integrantes do movimento como Umberto Boccioni, Antonio Sant'Elia, Volt, Virgilio Marchi, Enrico Prampolini, Mario Carli, E. Settimelli, Primo Conti, E. Odorizio, F. T. Marinetti, Pippo Oriani, Alberto Sartoris, Guido Fiorini, Cesare Poggi, e G. Lorenzi elaboraram manifestos e demais 
textos teóricos sobre o tema, em suas mais diversas variações. Além do desejo de renovação plástica e funcional dos edifícios e do relevo urbano, a arquitetura está simbolicamente ligada ao sentido de construção e/ou reconstrução futurista do universo, defendido em todas as áreas do conhecimento. Assim, desta forma, poderíamos dizer que praticamente todos os temas abordados nos escritos futuristas possuem um caráter arquitetônico, pois expressam a urgência da necessidade de reconstrução, edificação de novas formas de pensamento e atitude, remodelação plástica, reconfiguração de espaços, sejam estes materiais ou não.

Ao abordar - e procurar conciliar - os aspectos intangíveis, espirituais e misteriosos da existência do homem com aqueles de ordem material, arquitetônica e construtiva, conferindo a ambos o mesmo vigor de pesquisa e interesse, Fillia afirmou-se como um dos teóricos mais complexos, ricos e intrigantes do Futurismo, o que faz dele um personagem inesgotavelmente interessante.

\section{ARQUITETURA SACRA FUTURISTA (PREDOMÍNIO DO VIDRO E DO ALUMÍNIO)}

(Futurismo, vol. I, nº 4, Roma, 2 de outubro de 1932)

Os novos materiais de construção não se adaptam somente aos edifícios de caráter econômico, mas contém possibilidades reais de exploração estética não inferiores aos melhores resultados obtidos com os antigos materiais "nobres": estes não são negados pelos arquitetos modernos, mas a eles se somam os novos materiais que, na maioria dos casos, correspondem mais às exigências dos nossos tempos.

Enquanto, em um primeiro período, a revolução arquitetônica devia vencer as suas batalhas fundamentais no campo técnico e utilitário, hoje já se vislumbra a possibilidade de aproximar-se des temas mais dotados de lirismo e de inspiração, ou seja, temas nos quais a fantasia criativa não seja dependente de rigorosas necessidades práticas, nos quais o arquiteto tenha a liberdade de exprimir toda a potência do próprio estado de espírito, nos quais os novos meios e os novos materiais encontrem uma interpretação que lhes revele o esplendor da sua natureza.

As "Igrejas" são sem dúvida as construções nas quais o arquiteto pode almejar imprimir o máximo de individualidade. As Igrejas naturalmente exigem o respeito ao dogma: mas este nunca teve restrições de forma e são igualmente adequadas ao culto as arquiteturas mais diversas na História da Arte. 
Sant'Elia tinha sonhado em edificar grandes catedrais de concreto armado que dominassem a sua "cidade nova" com a sua poesia de audácia construtiva. A morte impediu a realização deste sonho. Mas hoje, em muitos países da Europa, já se perfilam os primeiros contornos de Igrejas coerentes com os bairros racionais das cidades. $\mathrm{O}$ ferro e o vidro são usados largamente e sem dano para o sentido religioso que, antes de qualquer outro valor, deve emanar desses edifícios: ao contrário, os novos materiais evitam o inconveniente gravíssimo de muitas construções antigas nas quais, pela dificuldade de transporte e pelo custo excessivo, se devia recorrer às "imitações" dos materiais "nobres", solução esta em contraste com o espírito construtivo de uma Igreja, que deve ser absolutamente puro.

Lembraremos as moderníssimas igrejas católicas de Basileia, Hamburgo, Berlim, Dusseldorf, etc. Muitos arquitetos como Holzmeister, Herkommer, Barting [sic], Berlage, Martin Weber ${ }^{1}$ etc. realizaram Igrejas totalmente racionais e imediatamente abertas ao culto. Todas estas construções naturalmente se ressentem do ambiente no qual foram criadas e, embora sigam as leis estruturais que hoje são comuns a todo o mundo, exigiriam outra interpretação para a nossa sensibilidade latina. Mas para a Alemanha e para o Norte da Suíça respondem plenamente à sua função e se harmonizam com o aspecto renovado das cidades.

Em outras Igrejas, já concluídas em outras cidades estrangeiras, embora domine um rígido senso racional de construção, há ainda um respeito por certas formas tradicionais que demonstra o medo de livrar-se de uma vez da que em outra época era a característica de um edifício religioso. Disto resulta, portanto, uma vaga nostalgia de outros estilos em contraste com o renovado espírito arquitetônico: o que é um absurdo porque a "religiosidade" de uma Igreja não é dada por certos contornos definidos, mas pelo ritmo geral do conjunto, pela harmonia poética dos volumes.

As novas Igrejas concebidas pelos arquitetos italianos, embora ainda não realizadas, demonstram uma inspiração infinitamente mais lírica.

E, junto com os arquitetos, todos os artistas inovadores italianos preocupam-se em alcançar nas novas igrejas uma unidade de estilo nunca obtida no exterior. Amadurece assim, em colaboração com os arquitetos, o caráter das Igrejas do século XX.

\footnotetext{
${ }^{1}$ Dentre os arquitetos e urbanistas citados neste trecho destacam-se: Clemens Holzmeister (1886 - 1983), arquiteto e cenógrafo austríaco; Hans Herkommer (1887-1956), arquiteto alemão; Hendrik Petrus Berlage (1856-1934), arquiteto e urbanista holandês, considerado o "pai da arquitetura moderna" em seu país; Martin Weber (18901941), arquiteto alemão célebre pelos projetos de igrejas católicas.
} 
A catedral de Alberto Sartoris é o exemplo mais grandioso de como deverá ser a arquitetura da Igreja moderna: triunfo do aço e do cristal, jogo de volumes, definindo um ritmo totalmente original e alcançando um resultado de rigor construtivo do mais alto significado.

Na Igreja Futurista idealizada por Fillia e Oriani o predomínio do vidro e do alumínio visa alcançar o máximo de leveza e neste projeto a luz é estudada como função estritamente arquitetônica. De modo similar, em outra Igreja, que Prampolini e Fillia estão projetando, procura-se interpretar arquitetonicamente o sentido de "aéreo" que hoje é a mais típica expressão da nossa civilização.

Todo este fervor criativo representa, portanto, a vontade dos arquitetos e dos artistas inovadores de dar ao nosso Tempo uma fisionomia que, na total aplicação dos novos materiais construtivos, interprete o espírito da Vida Moderna.

FILLIA 